

DOI: 10.12957/demetra.2018.32140

\title{
Informações para planejamento e elaboração de cardápios, contidas em editais de licitação de restaurantes universitários em universidades federais do Sul do Brasil
}

\author{
Information for menus planning and preparation contained in bidding documents for \\ university restaurants of federal universities in Southern Brazil
}

Samara de Cesaro Cavaler'

Mayara Aparecida Heilmann'

Ana Paula dos Santos'

Helder Calsavara Ferreira ${ }^{2}$

Elis Carolina de Souza Fatel ${ }^{3}$

1 Universidade Federal da Fronteira Sul, Curso de Nutrição. Realeza, PR, Brasil.

${ }^{2}$ Universidade Federal da Integração LatinoAmericana. Foz do Iguaçu, PR, Brasil.

${ }^{3}$ Universidade Federal da Fronteira Sul, Curso de Nutrição, Departamento de Nutrição. Realeza, PR, Brasil.

Correspondência / Correspondence

Samara de Cesaro Cavaler

E-mail: samara.cavaler@gmail.com

\section{Resumo}

Objetivo: Avaliar as informações para planejamento e elaboração de cardápios contidas nos editais de licitação dos restaurantes universitários de universidades federais do Sul do Brasil. Métodos: Estudo transversal com avaliação das informações contidas em editais de licitação, sobre o planejamento e a elaboração de cardápios de 35 Restaurantes Universitários das universidades federais do Sul do país, vigentes em 2015. Resultados: Em relação às informações per capita e de frequência, $34,3 \%$ dos editais contiveram informações para a realização de um planejamento adequado no que se refere à elaboração de cardápios; mais da metade dos editais não apresentou informações sobre aplicação de procedimentos técnicos apropriados de pré-preparo e preparo dos alimentos (54,29\%); a maioria dos editais não manifestou informações de incentivo à aquisição de produtos da Agricultura Familiar (85,71\%); nenhum edital exigiu obrigatoriedade da presença de Ficha Técnica de Preparo; mais da metade dos editais não contemplou cardápios para necessidades alimentares especiais $(57,14 \%)$; menos da metade dos editais determinou que o planejamento de cardápios respeitasse a cultura e o hábito alimentar local dos usuários $(45,71 \%)$. Foram verificadas diferenças significativas entre os estados da Região Sul do Brasil quanto às pontuações obtidas por meio do levantamento das informações sobre planejamento e elaboração de cardápios contidas nos editais de licitação das instituições de ensino superior. Conclusão: Verificou-se que os editais de licitação para contratação de empresas que forneçam e/ou produzam refeições aos acadêmicos, necessitam de melhor 
elaboração, abordando claramente itens básicos para um planejamento adequado dos cardápios.

Palavras-chave: Serviço de Alimentação. Restaurantes. Proposta de Concorrência.

\section{Abstract}

Objective: To assess, in bidding documents (BD) of university restaurants of federal universities in southern Brazil, information for menu planning and preparation. Methods: Cross-sectional study with evaluation of information about menus planning and preparation as specified in the BDs of 35 university restaurants of federal universities in South Brazil in 2015. Result: Regarding per capita information and frequency, $34.3 \%$ of the BDs contained requirements for proper planning and preparation of menus. More than half of the BDs had no information about application of appropriate technical procedures for food pre-preparation and preparation (54.29\%); most of the BDs did not provide information on incentives for acquisition of family farming products (85.71\%); no BD required mandatory food production datasheets; more than half of them did not include a requirement for special dietary needs (57.14\%); less than half of the documents determined that the menus planning should consider the local culture and dietary habits of users $(45.71 \%)$. There are significant differences among the states of southern Brazil for the scores obtained from information on menus planning and preparation specified in the BDs of public higher education institutions. Conclusion: It was found that the bidding documents for contracting companies that provide and / or produce meals to students of public higher education institutions need to be better outlined, clearly addressing basic items for proper menus planning and preparation.

Keywords: Food Services. Restaurants. Competitive Bidding.

\section{Introdução}

Estabelecimentos que fornecem refeições são conhecidos como Unidades Produtoras de Refeições (UPR). Estes locais podem ser de cunho comercial, como por exemplo, as lanchonetes e restaurantes, ou de caráter coletivo, chamados de Unidade de Alimentação e Nutrição (UAN), garantindo a oferta de alimentos e, sucessivamente, a prática de Segurança Alimentar e Nutricional. O espaço que fornece alimentação para a coletividade envolve grandes segmentos, e a alimentação escolar é um deles, podendo estar localizada em instituições como creches, escolas e universidades. ${ }^{1}$ 
As Instituições de Ensino Superior (IES) oferecem refeições para a coletividade acadêmica a um baixo custo, disponibilizadas em espaços públicos denominados de Restaurantes Universitários (RUs), ambientes que permitem a realização de refeições, bem como o convívio entre os acadêmicos, além de proporcionar a integração da universidade federal ao Programa Nacional de Assistência Estudantil (PNAES). Este programa apoia ações com a finalidade de facilitar a permanência dos jovens nas Instituições Federais de Ensino Superior (IFES). No quesito alimentação, o programa busca, a partir dos RUs, a oferta de refeições em quantidade e qualidade adequada aos estudantes, bem como preparações sensorialmente aceitas pelos consumidores, apresentando como um objetivo ofertar uma alimentação nutricionalmente equilibrada para melhorar o desempenho acadêmico e reduzir as taxas de evasão dos jovens da educação superior., ${ }^{2,3}$

Compete aos gestores que controlam os serviços de alimentação nos RUs almejarem sempre a satisfação dos usuários, através do planejamento e fornecimento de refeições nutritivas e saudáveis a preços acessíveis, além de estarem em equilíbrio com a disponibilidade financeira da empresa que administra o serviço. ${ }^{4-6}$

Por isso, para qualquer UPR, em especial para instituições de ensino, o cardápio é um instrumento de fundamental importância para o bom desempenho e funcionamento do serviço. Os cardápios dispõem de uma lista de preparações que irão compor a refeição preparada; além disso, são um meio para dar início ao processo produtivo, fornecendo, como subsídio, informações para que ocorra a aquisição dos ingredientes utilizados, conduzindo para seu pré-preparo e respectivo preparo, e oferecendo ao cliente produtos nutricionalmente adequados, saborosos e com uma avaliação positiva. ${ }^{7-10}$ Juntamente com o cardápio, uma unidade de alimentação deve dispor de fichas técnicas de preparo, visto sua utilização como um instrumento gerencial que oferece suporte operacional à empresa. A ficha técnica deve conter fatores de cocção, per capita, incidência, entre outros itens importantes para auxiliar na produção e gestão de uma unidade de alimentação. ${ }^{11}$

Outro aspecto importante se refere aos responsáveis pela execução do serviço de preparação das refeições, que devem estar atentos à realização dos procedimentos adequados para a produção das refeições e executar as Boas Práticas de Manipulação e Fabricação de Alimentos (BPF). ${ }^{12-14}$

Nas IES, as refeições são preparadas e servidas por empresas privadas, e por se tratar de uma prestação de serviços a órgãos governamentais, o processo de escolha de tais empresas deve ser feito por meio de licitação.

O dever de licitar está descrito na Constituição Federal, que em seu artigo 37, inciso XXI, prescreve:

XXI - ressalvados os casos especificados na legislação, as obras, serviços, compras e alienações serão contratados mediante processo de licitação pública que assegure igualdade de condições a todos os concorrentes, com cláusulas que estabeleçam obrigações de pagamento, mantidas as condições 
efetivas da proposta, nos termos da lei, o qual somente permitirá as exigências de qualificação técnica e econômica indispensáveis à garantia do cumprimento das obrigações. ${ }^{15}$

Devido à falta de estudo nesta área, o presente trabalho justifica-se pela busca em analisar, nos atos escritos oficiais (editais) de licitação dos RUs de universidades federais do Sul do Brasil, as informações referentes à execução de cardápios, a fim de verificar se estas são capazes de contemplar e oferecer subsídios importantes para a realização dos mesmos.

\section{Métodos}

Trata-se de estudo transversal realizado com os editais de licitação de todas as universidades federais dos estados da Região Sul do Brasil (Paraná, Santa Catarina e Rio Grande do Sul) e seus diferentes campi e/ou unidades que apresentavam edital de RUs em vigência no ano de 2015.

As universidades e o número de restaurantes que participaram do estudo, pertencentes ao Estado do Paraná, foram: Universidade Federal do Paraná (UFPR) com cinco RUs em funcionamento em diferentes campi/unidade; Universidade Federal da Fronteira Sul (UFFS), com um RU, e Universidade Tecnológica Federal do Paraná (UTFPR), que possui 11 RUs.

Em Santa Catarina, foram avaliadas a Universidade Federal da Fronteira Sul (UFFS), com um RU, e a Universidade Federal de Santa Catarina (UFSC), com quatro RUs.

Por fim, no Rio Grande do Sul estudaram-se os editais da Universidade Federal do Rio Grande (FURG), apresentando um RU; Universidade Federal da Fronteira Sul (UFFS), com dois RUs; Universidade Federal do Rio Grande do Sul (UFRGS), contendo um RU; Universidade Federal de Santa Maria (UFSM), com dois RUs, e Universidade Federal do Pampa (UNIPAMPA), com sete RUs.

A coleta de dados contemplou 35 editais e aconteceu entre os meses de dezembro de 2015 e fevereiro de 2016. Para a obtenção dos editais e posteriores análises, realizou-se pesquisa nas páginas on-line das instituições e/ou solicitação direta aos setores de compras e licitações das universidades participantes.

No presente trabalho, verificou-se a presença de itens essenciais para o planejamento e elaboração de cardápios, fundamentais à Administração Pública para o desenvolvimento de contratos administrativos eficientes e que não onerem demasiadamente uma das partes, no que tange aos princípios fundamentais para o planejamento e composição de um cardápio que possa atender ao público de forma satisfatória, oferecendo uma alimentação nutricionalmente equilibrada e de qualidade. 
Para um melhor entendimento da real situação dos editais estudados, aplicou-se um questionário, elaborado pelos pesquisadores, com 25 questões fechadas. Tais questões verificam os itens essenciais para um bom planejamento e elaboração de cardápios, como: frequência e per capita das preparações de prato principal, frequência e per capita das preparações de guarnição, frequência e per capita das preparações de salada, frequência e per capita das preparações de acompanhamento (arroz e feijão), frequência e per capita das preparações de sobremesa, frequência e per capita das preparações de bebida, aplicação de boas práticas de fabricação e manipulação de alimentos, aplicação de procedimentos técnicos adequados ao pré-preparo e preparo dos alimentos, aquisição de produtos da agricultura familiar, presença e obrigatoriedade de ficha técnica de preparo, distribuição de micronutrientes e fibras no cardápio, cardápios ou preparações para necessidades alimentares especiais, controle de sobras das refeições, pesquisa de satisfação com os usuários e cardápios que respeitem a cultura e hábito local.

Todas as questões foram organizadas em planilhas eletrônicas, para a análise de frequências e percentuais.

Além da aplicação de estatística descritiva, através de frequência e percentuais, as primeiras 22 questões (tabela 1) foram pontuadas pelos pesquisadores conforme sua classificação, somando um ponto para a presença de informação e zero ponto para ausência ou não disposição clara da informação. Após esta pontuação, foi realizado um ranking decrescente das IFES, identificadas nesta pesquisa por letras e números, isto é, de A a Ii; em seguida, realizaram-se testes não paramétricos (Kruskal-Wallis e Mann-Whitney) para a análise da variação das pontuações obtidas pelas IFES. Utilizou-se o software R Studio, ${ }^{16}$ versão 0.99 .473 , para verificar se havia diferença entre estados, referentes às informações contidas nos editais, dos 35 IFES, a um nível de $5 \%$ de significância.

Nas questões 23 e 24 (Tabela 2), as quais não foram pontuadas, os pesquisadores avaliaram respondendo com "sim" ou "não". O último ponto avaliado nesta pesquisa, questão número 25, foi sobre qual referência o edital utilizava para determinar macro e micronutrientes do cardápio, sendo esta respondida, pelos pesquisadores de maneira descritiva, a partir das análises dos editais. Conforme citado anteriormente, estas últimas questões foram demonstradas através de frequências e percentuais.

\section{Resultados}

Com a avaliação das informações para um planejamento adequado e elaboração de cardápios, foi verificado que nenhum dos 35 editais analisados apresentou $100 \%$ dos dados considerados importantes para um bom desempenho do funcionamento do serviço nos RUs. 
Quanto às informações sobre frequência da oferta das preparações de prato principal, observou-se que a maioria dos editais apresentou tal informação. Da mesma forma, a frequência da preparação de acompanhamento também esteve presente na maioria dos editais. Porém, as informações referentes às frequências das preparações de sobremesa e bebida foram as menos observadas nos editais avaliados (tabela 1).

Tabela 1. Informações para um planejamento adequado e elaboração de cardápio. RealezaPR, 2016.

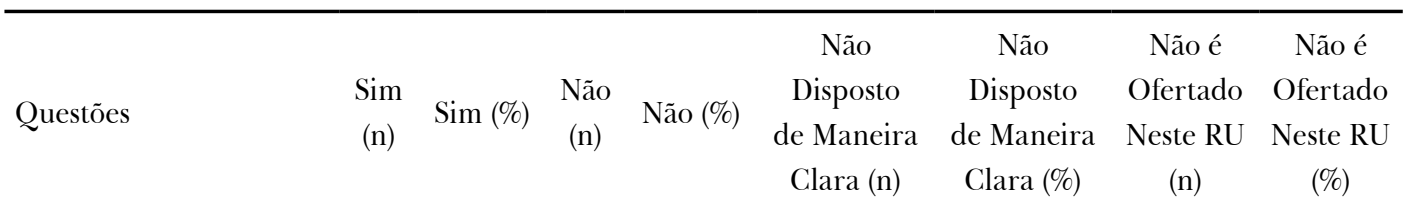

1 Este edital possui

frequência das preparações de prato principal?

$24 \quad 68,57 \% \quad 2 \quad 5,71 \%$

9

1 Este edital possui per capita das preparações do prato principal?

2 Este edital possui frequência das preparações de guarnição? $20 \quad 57,14 \% \quad 6 \quad 17,14 \%$ $12 \quad 34,29 \% \quad 22 \quad 62,86 \%$ 1 $2,86 \%$

$0 \quad 0,00 \%$

4 Este edital possui frequência das preparações de salada?

$20 \quad 57,14 \% \quad 6 \quad 17,14 \%$

9

$25,71 \%$

$0 \quad 0,00 \%$

$5 \quad$ Este edital possui per capita das preparações de salada?

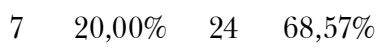

4

$11,43 \%$

$0 \quad 0,00 \%$

continua 


\begin{tabular}{|c|c|c|c|c|c|c|c|c|}
\hline Questões & $\begin{array}{c}\text { Sim } \\
(\mathrm{n})\end{array}$ & $\operatorname{Sim}(\%)$ & $\begin{array}{c}\text { Não } \\
\text { (n) }\end{array}$ & Não (\%) & $\begin{array}{c}\text { Não } \\
\text { Disposto } \\
\text { de Maneira } \\
\text { Clara (n) }\end{array}$ & $\begin{array}{c}\text { Não } \\
\text { Disposto } \\
\text { de Maneira } \\
\text { Clara (\%) }\end{array}$ & $\begin{array}{c}\text { Não é } \\
\text { Ofertado } \\
\text { Neste RU } \\
\text { (n) }\end{array}$ & $\begin{array}{c}\text { Não é } \\
\text { Ofertado } \\
\text { Neste RU } \\
(\%)\end{array}$ \\
\hline
\end{tabular}

$6 \quad$ Este edital possui frequência das preparações de acompanhamento (arroz e feijão)?

$7 \quad$ Este edital possui per capita das preparações de acompanhamento (arroz e feijão)? $12 \quad 34,29 \% \quad 22 \quad 62,86 \%$ 1 $2,86 \%$ $0 \quad 0,00 \%$

8 Este edital possui frequência das preparações de sobremesa?

$17 \quad 48,57 \% \quad 6 \quad 17,14 \%$

12

$34,29 \%$

$0 \quad 0,00 \%$

$9 \quad$ Este edital possui per capita das preparações de sobremesa? $2 \quad 5,71 \%$ $21 \quad 60,00 \%$ 12 $34,29 \%$ $0 \quad 0,00 \%$

10 Este edital possui frequência das preparações de bebida?

$10 \quad 28,57 * \% \quad 2 \quad 5,71 \%$ 22 $62,86 \%$ $1 \quad 2,86 \%$

11 Este edital possui per capita das preparações de bebida? $15 \quad 42,86 * \% \quad 3 \quad 8,57 \%$ 16 $45,71 \%$ $1 \quad 2,86 \%$

12 Este edital possui informações sobre aplicação de boas práticas de fabricação e manipulação de alimentos (BPF)?
$26 \quad 74,29 \% \quad 7 \quad 20,00 \%$
$25,71 \% \quad 0 \quad 0,00 \%$ 


\begin{tabular}{lccccccccc}
\hline & & & & & Não & Não & Não é & Não é \\
Questões & Sim & Sim (\%) & Não & Não (\%) & Disposto & Disposto & Ofertado & Ofertado \\
& de Maneira & de Maneira & Neste RU & Neste RU \\
& & & & & Clara (n) & Clara (\%) & $(\mathrm{n})$ & $(\%)$ \\
\hline
\end{tabular}

13 Este edital possui informações

sobre aplicação

de procedimentos

técnicos adequados

ao pré-preparo

e preparo dos

alimentos?

$16 \quad 45,71 \% \quad 19 \quad 54,29 \%$

0

$0,00 \%$

$0 \quad 0,00 \%$

14 Este edital possui

informações

sobre aquisição

de produtos da

agricultura familiar

$(\mathrm{AF})$ ?

4

$11,43 \% \quad 30$

$85,71 \%$

1

$2,86 \%$

$0 \quad 0,00 \%$

15 Este edital possui

obrigatoriedade da

presença de ficha

técnica de preparo

(FTP)?

$0 \quad 0,00 \%$

$35 \quad 100,00 \%$

0

$0,00 \%$

$0 \quad 0,00 \%$

16 Este edital possui

distribuição de

micronutrientes,

no cardápio, para

preparação das

refeições?

$1 \quad 2,86 \%$

$26 \quad 74,29 \%$

8

$22,86 \%$

$0 \quad 0,00 \%$

17 Este edital possui

distribuição de

fibras, no cardápio, para preparação das refeições?

$9 \quad 25,7 \% \quad 24 \quad 68,57 \%$

$2 \quad 5,71 \%$

$0 \quad 0,00 \%$

continua 


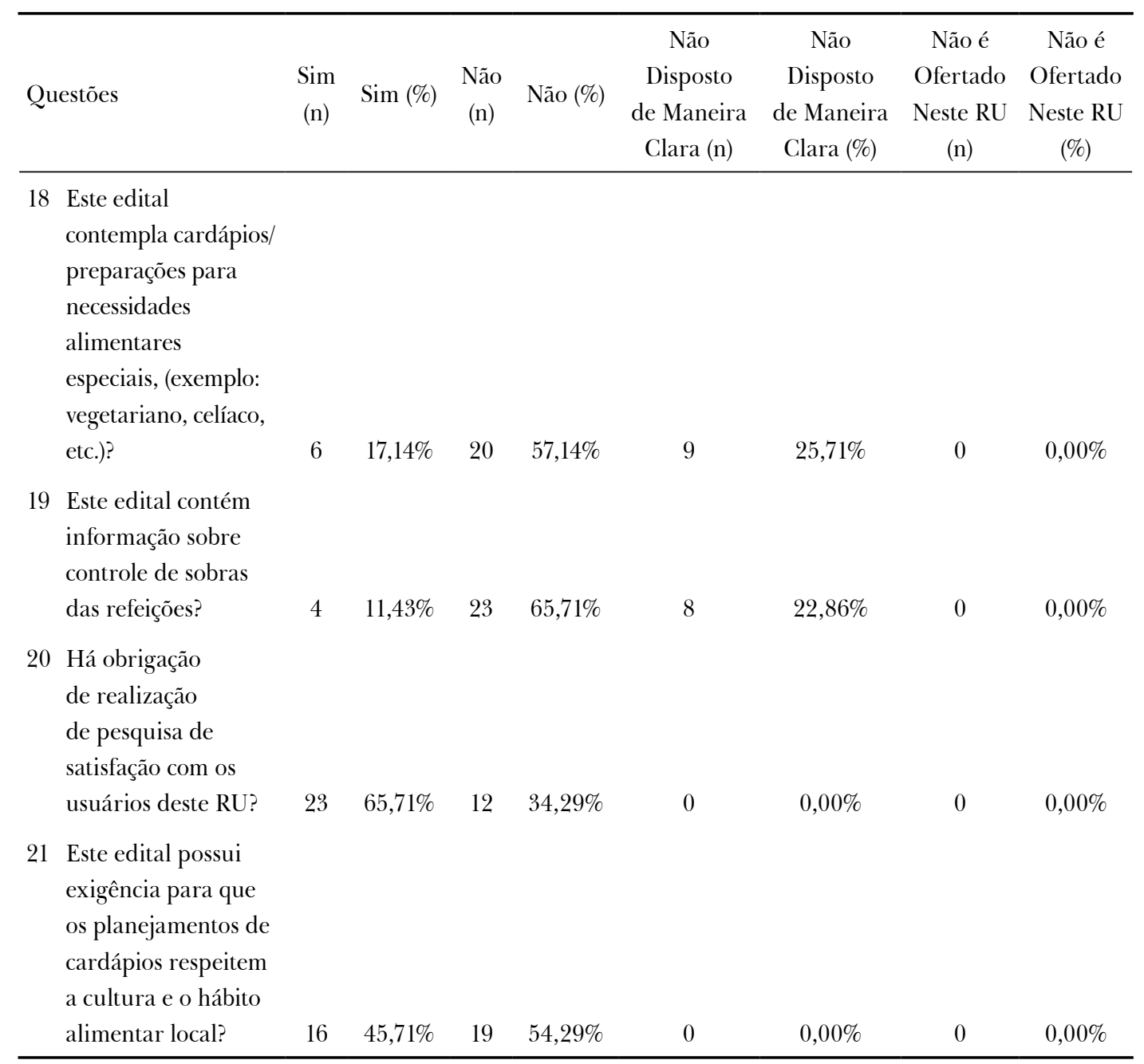

*Valores reais para a presença de informação descontando um edital que não serve a preparação bebida: Frequência SIM, 29,41\%; Per capita SIM, 44,11\%.

Em relação às informações referentes ao per capita do prato principal, foi constatado que a maioria dos editais apresenta este dado. A segunda preparação mais frequente em relação à informação contida no edital foi a de bebida. Já em relação à per capita da preparação de guarnição e acompanhamento, menos da metade dos editais apresentou este dado. Verificou-se que as duas preparações com menores informações de per capita foram as de salada e sobremesa (tabela 1). 
Observou-se que a maioria dos editais possui informações sobre aplicação de BPF de alimentos. No que diz respeito à aplicação de procedimentos técnicos adequados ao pré-preparo e preparo dos alimentos, mais da metade dos editais não apresentou esta informação. Em relação ao incentivo à aquisição de produtos da $\mathrm{AF}$, a maioria dos editais não mostrou tal informação, e $100 \%$ deles não exigiam obrigatoriedade da presença de FTP. Avaliou-se também que mais da metade não contemplou cardápios para necessidades alimentares especiais. Averiguou-se ainda que nem todos apresentaram informações sobre o controle de sobras das refeições. No que diz respeito à pesquisa de satisfação com os usuários e o planejamento de cardápios que respeitem a cultura e o hábito alimentar local da população, os dados não são apontados em todos os editais avaliados (tabela 1).

Quanto às referências utilizadas para determinar macro e micronutrientes do cardápio, menos da metade não apresentou informações relativas ao tema. Dos editais que dispuseram desta informação, a maioria utilizou como referência as informações para uma alimentação de adultos saudáveis e as informações do Programa de Alimentação do Trabalhador (PAT); apenas um edital estabeleceu percentuais recomendados como referência para uma alimentação equilibrada. Entretanto, estes dados não são especificados no edital (tabela 1).

A partir da análise dos itens 23 e 24, os pesquisadores chegaram à conclusão que não seria possível realizar um planejamento nutricional adequado para esta população e, com as informações de per capita e frequência das preparações contidas nos editais, apurou-se que na maioria dos RUs não seria possível realizar um planejamento adequado de cardápio (tabela 2).

Tabela 2. Informações sobre macro e micronutrientes, per capita e frequência das preparações, para um planejamento adequado e elaboração de cardápio. Realeza-PR, 2016

\begin{tabular}{lcccc}
\hline Questões & Sim (n) & Sim (\%) & Não (n) & Não (\%) \\
\hline $\begin{array}{l}\text { 23. Com as informações contidas neste edital, em } \\
\text { relação à distribuição de macro e micronutrientes, }\end{array}$ & 2 & $5,7 \%$ & 33 & $94,3 \%$ \\
é possível fazer um planejamento nutricional \\
adequado para esta população?
\end{tabular}


Também foram realizadas a classificação e a pontuação das IFES por estado. Verificou-se que a maior pontuação foi para os cinco editais das IFES do Estado do Paraná, os quais supostamente apresentaram maiores informações para um planejamento adequado e elaboração de cardápios em relação aos demais estados analisados.

Após a somatória total dos pontos referentes às 22 primeiras questões, averiguou-se a possibilidade de ocorrerem, ou não, diferenças significativas entre as pontuações obtidas pelas IFES pesquisadas dos estados da Região Sul do Brasil: Paraná, Santa Catarina e Rio Grande do Sul. Conforme demonstrado na Figura 1, os editais das IFES do Paraná apresentaram maiores pontuações, 13 pontos, e mediana em 12 pontos, em relação aos estados do Rio Grande do Sul, com 12 pontos e mediana em 10 pontos, e de Santa Catarina, menor pontuação com 5 pontos e mediana em 3 pontos. Desta forma, com análise estatística entre estados, verificou-se que entre o Estado do Paraná e o Estado do Rio Grande do Sul não há diferenças significativas entre as pontuações obtidas pelo levantamento das informações contidas nos editais das IES $\left(\mathrm{P}_{\text {valor }}>0,05\right)$; ambos apresentaram diferenças significativas em relação ao Estado de Santa Catarina $\left(\mathrm{P}_{\text {valor }}<0,05\right)$.

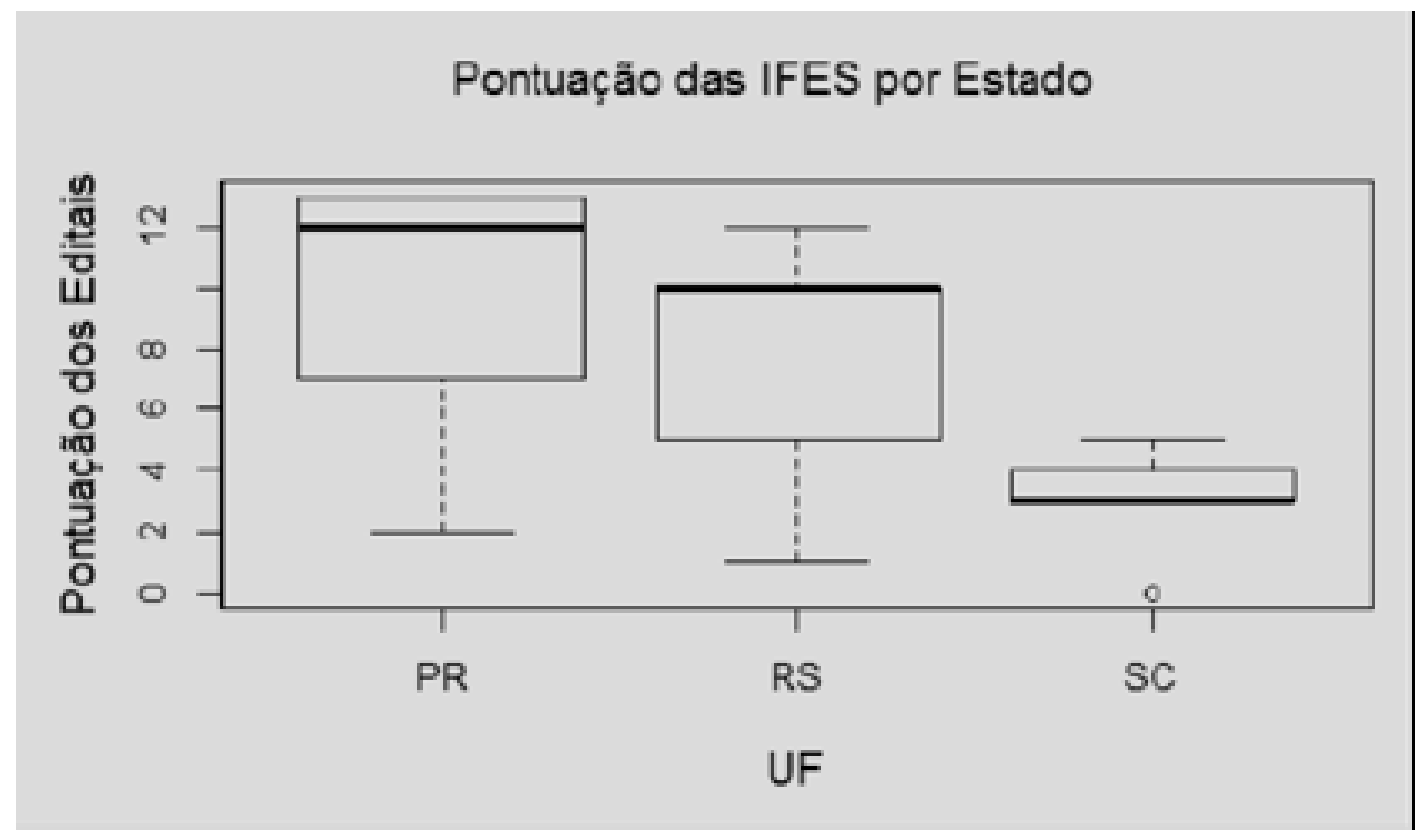

Teste estatístico Kruskal-Wallis para análise entre os três estados $\left(\mathrm{P}_{\text {valor }}<0,05\right)$. Teste estatístico de Mann-Whitney, entre estados, PR versus RS ( $\left.\mathrm{P}_{\text {valor }}>0,05\right)$; PR versus $\mathrm{SC}\left(\mathrm{P}_{\text {valor }}<0,05\right)$ e RS vesus $S C\left(\mathrm{P}_{\text {valor }}<0,05\right)$.

Figura 1. Pontuação obtida após a análise dos editais de cada IFES avaliada, em função da Unidade da Federação (UF) de origem. Realeza-PR, 2016. 


\section{Discussão}

Os resultados encontrados a partir da presente pesquisa evidenciaram lapsos importantes na elaboração dos editais referentes a implantação e/ou funcionamento dos RUs na Região Sul do Brasil, que interferem diretamente na execução do serviço de um restaurante e no auxílio da produção das refeições à comunidade acadêmica.

De acordo com os dados associados à presença de informações de frequência e per capita das preparações básicas de um cardápio simples, composto por prato principal, guarnição, salada, acompanhamento (arroz e feijão), sobremesa e bebidas, foram registrados baixos percentuais da presença desses valores nos editais, visto que estes dados devem estar dispostos claramente para assegurar um bom planejamento do preparo das refeições. A utilização de informações como frequência e per capita das preparações garante a realização dos cálculos para a elaboração de um cardápio e sua respectiva avaliação do equilíbrio nutricional entre as preparações, além de auxiliar na previsão de compras necessárias, servindo como parâmetro no controle de desperdício de alimentos. ${ }^{8-11}$ Em vista disso, é analisada a chance de graves problemas na produção e no oferecimento das refeições aos usuários, como consequência dos percentuais altos que não foram dispostos de maneira clara ou não apresentaram essa informação nos editais.

Verificou-se que nem todos os editais de licitação de RUs apresentaram informações sobre aplicação de BPF, podendo, com isso, gerar possíveis riscos para a produção e qualidade dos alimentos e, consequentemente, prejudicar a saúde dos clientes. As execuções de BPF de alimentos são condutas de organização e higiene adotadas em todos os estabelecimentos que produzem e/ou fornecem refeições para garantir a oferta de alimentos seguros à população. ${ }^{12,17,18}$

Diante da questão sobre a presença de informações de aplicação de procedimentos técnicos adequados ao pré-preparo e preparo dos alimentos, observou-se um percentual baixo de editais que atenderam a este quesito. Isso pode gerar negligência na produção das refeições, pois a literatura mostra que as etapas de pré-preparo e preparo são fundamentais para a diminuição do desperdício, orientações e supervisões do processo de produção e para o controle do processo de limpeza, descasque e corte dos vegetais..$^{19,20}$

Foi possível avaliar um percentual muito baixo de editais de licitação de RUs que incentiva a aquisição de alimentos da AF. Entretanto, destaca-se que apenas em 1o de janeiro de 2016 entrou em vigor o Decreto no 8.473, de 22 de junho de 2015, ${ }^{21}$ que estabelece a aquisição mínima de pelo menos $30 \%$ de gêneros alimentícios para a produção de refeições em RUs, de agricultores familiares e suas organizações, empreendedores familiares rurais e demais beneficiários que se enquadrem na Lei no 11.326 , de 24 de julho de $2006,{ }^{22}$ pelos órgãos e entidades da Administração Pública Federal direta, autárquica e fundacional. 
Sobre as informações referentes à FTP, observou-se que nenhum edital fez menção sobre este assunto. Percebe-se a importância de uma FTP como um instrumento gerencial de apoio operacional, possibilitando que sejam feitos orçamentos dos custos, a ordenação do preparo e o cálculo do valor nutricional da preparação, além de definir ingredientes e quantidades a serem empregadas, modo de preparo, bem como fator de correção e cocção dos alimentos, custo da produção, valor calórico por porção, per capita e informação nutricional. ${ }^{23,24}$

Outro ponto levantado e que merece destaque é o pequeno percentual de editais que contemplaram cardápios diferenciados para atender comensais com necessidades alimentares especiais. Tal dado é preocupante frente aos levantamentos do Instituto Brasileiro de Opinião Pública e Estatística de 2012, que destaca que $8 \%$ dos brasileiros declaram não consumir nenhum tipo de carne, ${ }^{24}$ Já o percentual de alergias alimentares da população mundial está entre 2 e $4 \%$ de adultos, e mais de $45 \%$ sofrem com sintomas de algum tipo de intolerância a alimentos ${ }^{25}$

No que diz respeito ao controle de sobras das refeições, observa-se que mais da metade dos editais não trazem informações sobre esta questão. De acordo com a Resolução da Diretoria Colegiada - RDC no 216, de 15 de setembro de 2004, só é permitido o reaproveitamento de sobras se a cadeia de resfriamento, aquecimento e o prazo máximo de consumo do alimento preparado e conservado forem adequados. ${ }^{17}$

Neste trabalho, foi avaliada a baixa presença de informações em editais de licitação, referentes à obrigatoriedade de aplicação de pesquisa de satisfação com os usuários dos RUs, a qual teve por objetivo avaliar o desempenho do estabelecimento a partir do ponto de vista do cliente e, portanto, avaliar as necessidades de melhorias do local. ${ }^{26}$

Avaliou-se também uma baixa presença de editais que adotaram as exigências para a elaboração de cardápios que respeitem a cultura e o hábito alimentar local dos usuários, visto que no país há grande diversidade de culturas culinárias e buscam-se o incentivo e o respeito às referências nutricionais, aos hábitos alimentares, à cultura e à tradição alimentar, contribuindo para a valorização das especificidades locais. Isso tudo se vincula ao fortalecimento das identidades sociais, sempre consolidando a concepção do respeito à diversidade cultural e aos hábitos alimentares locais. Apesar de ser notável que o ingresso na faculdade modifique os hábitos alimentares dos estudantes, verifica-se a importância do incentivo à valorização da cultura e dos hábitos alimentares da população. ${ }^{27}$

Quanto aos parâmetros utilizados para determinação dos valores de macro e micronutrientes para composição nutricional dos cardápios planejados e elaborados, para os usuários dos RUs das IFES do Sul do país avaliou-se que nenhuma informação é específica para o público acadêmico, visto que os RUs devem alcançar os objetivos nutricionais das refeições coletivas, ou seja, estar de acordo com as recomendações nutricionais diárias dos usuários que frequentam esses estabelecimentos. ${ }^{28,29}$ 
A partir disso, é notória a necessidade de estabelecer valores nutricionais específicos de macro e micronutrientes recomendados diariamente para o público acadêmico que realiza suas refeições nos RUs do Brasil.

Com relação à presença de informações sobre a distribuição de macro e micronutrientes, analisou-sea impossibilidade de realizar cardápios nutricionalmente adequados ao público que frequenta os RUs. A literatura mostra que para o planejamento da alimentação, é fundamental determinar as informações nutricionais mínimas de nutrientes para a elaboração de um cardápio balanceado, a fim de fornecer uma refeição nutricionalmente equilibrada. ${ }^{30}$

Em relação ao ranking dos editais das IFES, após a pontuação atribuída às universidades, foi averiguado que as maiores informações para o planejamento e elaboração de cardápios estão no conjunto de editais das universidades do Estado do Paraná, seguido do Estado do Rio Grande do Sul. Foi avaliado que em unidades que preparam a alimentação, o planejamento das etapas executadas é de fundamental importância para o padrão de qualidade dos processos de produção, seguindo os critérios e características próprias do estabelecimento, principalmente no que diz respeito ao planejamento e elaboração de cardápios. ${ }^{23}$

Neste estudo, não foi possível avaliar quais profissionais estão envolvidos na elaboração destes editais de licitação; desta forma, mais estudos que correlacionem as variáveis: equipe de servidores envolvidos na elaboração de editais de licitação versus qualidade das informações destes editais são importantes para elucidar esta questão. Imagina-se que na equipe multiprofissional que elabora estes atos oficiais deve haver profissionais da área da Nutrição, o que justificaria editais mais bem elaborados no que diz respeito ao planejamento e à elaboração de cardápios. Além disso, cria-se a hipótese de que as IFES utilizam, como referências para elaboração de seus editais, modelos de editais de IFES do seu próprio estado, podendo assim justificar o resultado do ranking.

\section{Conclusão}

Destaca-se a necessidade da definição de critérios padrões para elaboração de editais de licitação de RUs, a fim de minimizar supostos erros que aparecem nestes documentos e que, direta ou indiretamente, interferem no serviço e na produção das refeições para a comunidade acadêmica. Após este estudo, os pesquisadores sugerem que os editais devam conter, no mínimo, as seguintes informações para um bom planejamento e elaboração de cardápios para RUs: informações sobre frequência e per capita de todas as preparações servidas; orientações a serem seguidas sobre BPF dos alimentos e controle de sobras; orientações sobre técnicas de pré-preparo e preparo dos alimentos; informações de aquisição de produtos da AF; sugerir que os responsáveis técnicos dos RUs elaborem FTP; contemplar em sua redação uma distribuição de macro e micronutrientes e fibras adequados a esta população; sugerir opções de cardápios para pessoas com necessidade 
alimentares especiais e opções de cardápios que respeitem a cultura e os hábitos alimentares locais; exigir que seja realizada pesquisa de satisfação com os usuários do serviço.

Conclui-se que, possivelmente, os erros e falhas referentes ao planejamento e elaboração de cardápios, presentes nestes documentos, sejam pela falta de conhecimento das pessoas envolvidas na sua elaboração. Por isso, salienta-se que é de fundamental importância o envolvimento do profissional nutricionista e do responsável técnico da unidade de alimentação na elaboração dos editais de licitação dos RUs, garantindo que pontos importantes a serem avaliados para um bom planejamento e elaboração de cardápios não faltem nestes editais, para que sejam garantidas uma boa execução do serviço e a oferta de refeições adequadas, no aspecto higiênico-sanitário, sensorial e nutricional.

Desta forma, verificou-se que nem todos os editais são eficientes para oferecer uma alimentação de qualidade aos estudantes.

\section{Colaboradores}

Cavaler SC participou da escrita do artigo; Heilmann MA, Santos AP participaram da coleta dos dados e elaboração do trabalho; Ferreira HC participou da análise estatística e interpretação dos dados e Fatel ECS, participou da elaboração, desenho e revisão crítica do artigo.

Conflito de interesses: Os autores declaração não haver conflito de interesses.

\section{Referências}

1. Sant'ana HMP. Planejamento físico-funcional de unidades de alimentação e nutrição. Rio de Janeiro: Rubio; 2012.

2. Brasil. Decreto n ${ }^{\circ}$ 7.234, de 19 de julho de 2010 Dispõe sobre o Programa Nacional de Assistência Estudantil - PNAES. Diário Oficial da União. 20 jul. 2010.

3. Junior FJM, Pafiadache C, Loose LH, Piaia R, Scher VT, Peripolli A, et al. Satisfação dos usuários do Restaurante Universitário da Universidade Federal de Santa Maria: uma análise descritiva. Rev. Sociais e Humanas, Santa Maria. 2015; 28(02):83-108.

4. Maia TML. Planejamento e gestão estratégica para o restaurante universitário da UFC em um cenário de expansão do número de alunos [Dissertação]. [Fortaleza]: Universidade Federal do Ceará; 2008.

5. Abreu ES, Spinelli MGN, Pinto AMS. Gestão de unidades de alimentação e nutrição: um modo de fazer. $6^{a}$ ed. São Paulo: Metha; 2016.

6. Hörbe TAN, Moura GL, Silva AH, Vargas KS, Machado EC. Gestão por processos: uma proposta de melhoria aplicada a uma pequena empresa do ramo de alimentação. Revista Eletrônica Sistemas \& Gestão. 2015; 10(2):226-237. 
7. Amorin MMA, Junqueira RG, Jokl L. Adequação nutricional do almoço self-service de uma empresa de Santa Luzia, MG. Rev Nutr. 2005; 18(1):145-154.

8. Rosa COL, Monteiro MRP. Unidades produtoras de refeições: uma visão prática. Rio de Janeiro: Rubio; 2014.

9. Teichmann IM. Cardápios: técnicas e criatividade. 7. ed. Caxias do Sul: Educs; 2009.

10. Akutsu RC, Botelho RA, Camargo EB, Sálvio KEO, Araújo WC. A ficha técnica de preparação como instrumento de qualidade na produção de refeições. Rev Nutr. 2005; 18(2):277-279.

11. Romero GR, Angst CA, Basso C, Mesquita M, Back C. Serviço de alimentação e nutrição hospitalar: Elaboração de fichas técnicas. Disciplinarum Scientia. 2015; 16(2): 265-273.

12. Libânio MM, Gondim CM, Sousa JBG. Elaboração do manual de boas práticas do restaurante universitário da universidade federal de Campina Grande, Campus Cuité-PB. Volume 2. Revista FAMA de Ciências da Saúde. 2015; 1(2):40-53.

13. Silveira JT, Brasil CCB, Floriano JM, Garcia MV. Higiene dos serviços de alimentação no Brasil: uma revisão sistemática. Saúde em Revista. 2016; 16(42):57-69.

14. Franklin TA, Sena AS, Santana MLAD'A, Matos TB, Milagres MP. Segurança alimentar, nutricional e sustentabilidade no restaurante universitário. Revista Saúde.Com. 2016; 12(1):482-487.

15. Brasil. Constituição (1988) Constituição da República Federativa do Brasil. art. 37, inciso XXI, da Constituição Federal, institui normas para licitações e contratos da Administração Pública e dá outras providências. Brasília: Senado Federal; 1988.

16. Rstudio. RStudio, version 0.99.473 de 12 ago. 2015. RStudio, 2015. [acesso em: 13 ago. 2015]. Disponível em: https://www.rstudio.com

17. Brasil. Ministério da Saúde. Resolução da Diretoria Colegiada no 216, 15 de setembro de 2004. Dispõe sobre regulamento Técnico de Boas Práticas para Serviços de Alimentação. Diário Oficial da União. 16 set. 2004.

18. Brasil. Ministério da Saúde. Resolução da Diretoria Colegiada no 275 de 21 de outubro de 2002. Aprova o Regulamento Técnico de Procedimentos Operacionais Padronizados Aplicados aos Estabelecimentos Produtores/Industrializadores de Alimentos e a Lista de Verificação de Boas Práticas de Fabricação em Estabelecimentos. Produtores/Industrializadores de Alimentos. Diário Oficial da União. 23 out. 2002; 1:126.

19. Goes VF, Valduga L, Soares BM. Determinação e Avaliação do Fator de Correção de Hortaliças em uma Unidade de Alimentação e Nutrição de Guarapuava - PR. Revista UNOPAR Cientifica Ciências Biológicas e da Saúde. 2013; 15(Esp):339-342.

20. Spinelli MGN, Cale LR. Avaliação de resíduos sólidos em uma unidade de alimentação e nutrição. Rev Simbio-Logias. 2009; 2(1):21-30.

21. Brasil. Presidência da República. Casa Civil. Decreto n. 8.473, de 22 de junho de 2015. Estabelece no âmbito da Administração Pública federal, o percentual mínimo destinado à aquisição de gêneros alimentícios de agricultores familiares e suas organizações, empreendedores familiares rurais e demais beneficiários da Lei no 11.326, de 24 de julho de 2006, e dá outras providências. Diário Oficial da União. 23 jun. 2015. 
22. Brasil. Presidência da República. Casa Civil. Lei n. 11.326, de 24 de julho de 2006. Estabelece as diretrizes para a formulação da Política Nacional da Agricultura Familiar e Empreendimentos Familiares Rurais. Diário Oficial da União. 25 jul. 2006.

23. Castro DS, Marques LF, Nunes JS, Silva LMM, Souza FC, Moreira IS, et al. Implantação de Fichas Técnicas de Preparo para a Padronização de Processos Produtivos em UAN. Informativo Técnico do Semi-Árido. 2013; 7(1):106-110.

24. Freitas CFC, Peralta AM, Carvalho AM, Carioca AAF, Fisberg RM, Marchioni DML. Qualidade da dieta entre consumidores e não consumidores de carnes vermelhas e processadas: estudo ISA-Capital. Rev Nutr. 2015; 28(6):681-689.

25. Ramos REM, Lyra NRS, Oliveira CM. Alergia alimentar: reações e métodos diagnósticos. J Manag Prim Health Care. 2013; 4(2):54-63.

26. Moreira Junior FJ, Pafiadache C, Loose LH, Piaia R, Scher VT, Peripolli A, et al. Satisfação dos usuários do restaurante universitário da universidade federal de Santa Maria: uma análise descritiva. Rev Sociais e Humanas. 2015; 28(02):83-108.

27. Paiva JB, Freitas MCS, Santos LAS. Hábitos alimentares regionais no Programa Nacional de Alimentação Escolar: um estudo qualitativo em um município do sertão da Bahia, Brasil. Rev. Nutr. 2012; 25(2):191-202

28. Oliveira RB, Guaglianoni DG, Demonte A. Perfil do usuário, composição e adequação Nutricional do cardápio oferecido em um Restaurante universitário. Revista de Alimentação e Nutrição. 2005; 16(4):397-401.

29. Hartmann Y. Avaliação do consumo alimentar de estudantes frequentadores do Restaurante Universitário da Universidade de Brasília [Dissertação]. [Brasília]: Faculdade de Ciências da Saúde, Universidade de Brasília; 2015.

30. Barrozo ALP, Mendonça KAN. Análise qualitativa de preparações de cardápios de uma unidade de alimentação e nutrição em Brasília. Revista Universitas: Ciências da Saúde. 2015; 13(2):87-92.

Recebido: 08 de janeiro, 2018

Revisado: 16 de julho, 2018

Aceito: 26 de julho, 2018 
